\title{
Preface: neural networks, nonlinear dynamics, and risk management in banking and finance
}

\section{Duc Khuong Nguyen ${ }^{1,2} \cdot$ Hans-Jörg von Mettenheim ${ }^{1,3} \cdot$ Charalampos Stasinakis $^{3,4}$}

Accepted: 25 November 2020 / Published online: 5 January 2021

(c) The Author(s), under exclusive licence to Springer Science+Business Media, LLC part of Springer Nature 2021

When we launched the call for papers for this special issue in November 2018, we could hardly imagine what state the World would be in, just two years later, when writing this editorial for the completed work in November 2020. In some ways, the current Covid-19 pandemic shows the necessity for the methods and results outlined in 15 highly creative and innovative papers that have been retained. What we are witnessing is a prime example for nonlinear dynamics at work. It goes without saying that adequate risk management methods have been and remain of utmost importance for navigating through the financial markets during the turbulent year of 2020.

We are happy and proud to bring a wide array of state-of-the-art research to the reader written by diverse author teams. A clear focus of the special issue can be found in the application of machine learning techniques that are recurrent topics in the special issue's articles. Equally, the theme of cryptocurrencies and their dynamics emerges. Finally, the papers also cover macro-economic topics such as Brexit, the behavior of bond markets and sovereign credit ratings.

The selected papers have strong ties to two major finance conferences that have established and proven themselves over the years. Firstly, our issue features reworked papers from the 25 th International Conference on Forecasting Financial Markets that was organized in cooperation with the Oxford-Man Institute of Quantitative Finance and took place in Said Business School, University of Oxford. Secondly, the issue includes publications from the 2018 Vietnam Symposium on Banking and Finance that took place in the wonderful old imperial capital city of Hue, Vietnam, and that was co-organized by the Association of Vietnamese Scientists and Experts (AVSE Global) and the Hue College of Economics.

We firmly believe that the special issue's papers, written by some of the leading experts in the field of nonlinear dynamics, complexity, and machine learning in finance, will be of wide interest to academic researchers and finance professionals alike. Their methodologies and findings may also encourage further research in a variety of challenging issues for the global financial markets associated with not only a post-Covid but also a post-Brexit environment.

\footnotetext{
$\bowtie$ Duc Khuong Nguyen duc.nguyen@ipag.fr

1 IPAG Business School, Paris, France

2 International School, Vietnam National University, Hanoi, Vietnam

3 Keynum Investments, Rennes, France

4 University of Glasgow, Glasgow, UK
} 
We would like to thank Editor-in-Chief, Professor Endre Boros, for providing us an excellent opportunity to actively contribute to the development of Annals of Operations Research through this collection of high-quality papers in a special issue. We are also grateful to all the contributors for their innovative papers and the anonymous reviewers for their rigorous reviewing reports as well. Finally, our thanks go to the journal's Publications Managers, Ms. Katie D'Agosta and Ms. Ann Pulido, for their helpful assistance during the whole editorial process.

Publisher's Note Springer Nature remains neutral with regard to jurisdictional claims in published maps and institutional affiliations. 